\title{
Evaluation of Field Desorption Mass Spectrometry for the Analysis of Polyethylene*
}

\author{
William J. Evans, Donna M. DeCoster, and John Greaves \\ Department of Chemistry, University of California-Irvine, Irvine, California, USA
}

Field desorption mass spectrometry (FD-MS) has been evaluated for the analysis of low molecular weight polyethylene by using samples in the molecular weight range 600-2000 u as determined by gel permeation chromatography. The repeat units and end group's were characterized by FD-MS, but it was demonstrated that accurate molecular weight distribution data cannot be obtained for polyethylene by FD-MS because there is mass discrimination against the higher molecular weight polymers. (J Am Soc Mass Spectrom 1996, 7, 1070-1074)

$\mathrm{F}$ Tield desorption mass spectrometry (FD-MS) which was reported initially in 1969, was the first desorption ionization method to be used in mass spectrometry [1]. FD-MS is a variation of field ionization mass spectrometry (FI-MS). In FI-MS, a gas is passed over an activated emitter, whereas in FD-MS samples are placed directly on the emitter. The emitter consists of a $10-\mu \mathrm{m}$ tungsten wire on which pyrolytic carbon microneedles were grown. The emitter is held at the accelerating potential and is situated within a few millimeters of a counterelectrode, which is at a negative potential. Under these conditions, the high field strengths necessary for field ionization $\left(10^{7}\right.$ to $10^{8}$ $\mathrm{V} / \mathrm{cm}$ ) are generated near the tips of the carbon microneedles. This results in quantum mechanical tunneling of a valence electron from the sample producing cationic $[\mathrm{M}]^{+\cdot}$ radicals, although for more polar analytes cationic attachment $\left(\left[\mathrm{MH}^{+}, \mathrm{MNa}^{+}\right]\right)$is also a common means of ion formation. Because the $[\mathrm{M}]^{+\cdot}$ species are not in a highly excited state, little or no fragmentation occurs and molecular ions are abundant $[2,3]$. The tungsten wire is resistively heated to aid in the desorption of the ions.

FD-MS can be applied to the analysis of polymeric samples and has several potential advantages over conventional techniques. Of primary importance in characterizing polymers is information on the repeat unit, the end group, and the number and weight average molecular weights. Although gel permeation chromatography (GPC) provides a chromatogram of a molecular weight distribution, it gives no information on the individual chains that comprise the polymer. Similarly, NMR spectroscopy gives a summation of resonances in the polymer, rather than data on separate components. Because FD-MS gives the molecular

Address reprint requests to William J. Evans, Department of Chemistry, University of California-Irvine, Irvine, CA 92717-2025.

-Originally presented at the 43rd Annual Conference of the American Society of Mass Spectrometry, Atlanta, GA, May 1995. weight of each individual polymer chain in the sample, it can provide data on the repeat unit and end group that is not obtainable by the other methods. This information aids considerably in determination of the polymer composition and the initiation, propagation, and termination processes that are involved.

FD-MS has the additional advantage that it is a very gentle ionization technique that gives primarily the molecular ion. In the case of polyethylene, there is a small amount of fragmentation that involves loss of $\mathrm{H}_{2}$ [3]. In contrast, chemical and electron ionization cause extensive fragmentation of long chain hydrocarbons such as polyethylene. Furthermore, FD-MS can be used on nonpolar samples, whereas other ionization techniques such as liquid secondary ion mass spectrometry (LSIMS) work well on more polar samples. Matrixassisted laser desorption ionization-Fourier transform mass spectrometry of polyethylene has been reported, but difficulty in analyzing this polymer compared with other hydrocarbon polymers was noted [4].

FD-MS has been shown to be effective to determine polymer characteristics for polymeric standards of polybutadiene [5, 6], polyisoprene [6], and polystyrene [6-8] and to give accurate molecular weight distributions equivalent to those obtained by conventional techniques such as GPC $[7,8]$. However, the ability of FD-MS to give accurate number and weight average molecular weight for polyethylene was not investigated fully. We report here results of a study of the accuracy of FD-MS to determine the molecular weight distribution of low molecular weight polyethylene.

\section{Experimental}

\section{Samples}

Polyethylene and polystyrene standards were purchased from Scientific Polymer Products, Inc. Eicosane $\left(\mathrm{C}_{20} \mathrm{H}_{42}\right)$, triacontane $\left(\mathrm{C}_{30} \mathrm{H}_{62}\right)$, and tetratriacontane $\left(\mathrm{C}_{34} \mathrm{H}_{70}\right)$ were purchased from Aldrich Chemical Co. 
(Milwaukee, WI). Toluene- $d_{8}(99.6 \% \mathrm{D})$ was obtained from Cambridge Isotope Laboratories (Woburn, MA). All products were used as received.

\section{Instrumentation}

Mass spectra were obtained on a Fisons (Danvers, MA) Autospec mass spectrometer with a high field (4500-u) magnet. The instrument was operated at an acceleration potential of $8 \mathrm{kV}$ with an extraction voltage of $-4 \mathrm{kV}$. No source heater was used and the source temperature was $25^{\circ} \mathrm{C}$. Alignment of the probe and instrument tuning were achieved by using the $\mathrm{m} / \mathrm{z} 58$ ion of acetone generated by field ionization. The resolving power was 1500 and scanning was from $\mathrm{m} / z$ 4400 to 100 at $7 \mathrm{~s}$ per decade. The emitter (LindenChromasspec, Princeton, NJ) was loaded by dipping into a $10-\mathrm{mg} / \mathrm{mL}$ solution of the sample in hot toluene. The emitter current was programmed from 0 to $50 \mathrm{~mA}$ at $1 \mathrm{~mA} / \mathrm{min}$ after a $1-\mathrm{min}$ delay. Data were collected in continuum mode for $50 \mathrm{~min}$ (i.e., all data points were collected and stored rather than being centroided prior to storage) and all scans were averaged to obtain the profile of the polymer chains. Calibration was with cesium iodide by using LSIMS.

${ }^{1} \mathrm{H}$ NMR spectra were obtained on GE QE $300-\mathrm{MHz}$ or GN $500-\mathrm{MHz}$ NMR spectrometers (Fremont, CA) and chemical shifts were assigned relative to internal solvent resonance $\left(\mathrm{C}_{6} \mathrm{D}_{5} \mathrm{CD}_{2} \mathrm{H}\right.$ at $\left.2.09 \mathrm{ppm}\right)$. The ${ }^{1} \mathrm{H}$ NMR spectra of the polymer samples were obtained at $110^{\circ} \mathrm{C}$ in toluene- $d_{8}$ with a delay time of $15 \mathrm{~s}$. The number average molecular weight $\left(M_{n}\right)$ can be calculated from the areas of the methylene peak $\left(M_{1}\right)$ and the methyl peak $\left(M_{2}\right)$ by using the equation $M_{n}=$ $42\left(M_{1} / M_{2}\right)+30$. This assumes that the polymer is linear, which is consistent with the NMR data.

\section{Results and Discussion}

The applicability of FD-MS to analysis of low molecular weight polyethylene was assessed by using three different commercially available polyethylene standards and then by comparing the FD-MS data with data obtained for polystyrene. Table 1 shows the manufacturer's number average $\left(M_{n}\right)$ and weight average molecular weight $\left(M_{\mathrm{w}}\right)$ data as determined by GPC and the number average molecular weight data as determined by NMR and FD-MS for the polyethylene samples and for mixtures of these samples. The $M_{n}$ values obtained by ${ }^{1} \mathrm{H}$ NMR spectroscopy by integration of methyl and methylene signals typically were higher than those obtained by GPC. This observation was especially true for the highest molecular weight sample and was likely to be due to the difficulty in integrating the diminishing methyl signal as the chain length of polyethylene increased.

Full FD-MS data are shown in Figures 1 and 2. The averaged FD-MS data for the polyethylene show a series of polymer chains. The molecular ions $[\mathrm{M}]^{+}$of
Table 1. Analysis of polyethylene standards

\begin{tabular}{lcccc}
$\begin{array}{l}\text { Standard } \\
\text { polyethylene }\end{array}$ & $\begin{array}{c}\text { NMR }\left(M_{n}\right) \\
(u)\end{array}$ & $\begin{array}{c}\text { FD-MS }\left(M_{n}\right) \\
(u)\end{array}$ & $\begin{array}{c}\text { GPC }\left(M_{n}\right) \\
(u)\end{array}$ & $\begin{array}{c}\text { GPC }\left(M_{w}\right) \\
(u)\end{array}$ \\
\hline \hline A & 870 & 535 & 680 & 800 \\
B & 1400 & 955 & 960 & 1150 \\
C & 3200 & $1852 / 675^{\circ}$ & 1870 & 2150 \\
\hline \hline Mixture & & & Calculated \\
(molar ratio) & & & $M_{n}$ \\
\hline \hline A:3C & 1824 & 563 & 1576 \\
A: $14 C$ & 2707 & 563 & 1788 \\
\hline
\end{tabular}

${ }^{a} 1852=M_{n}$ for higher molecular fraction; $675=M_{n}$ for bimodal distribution.

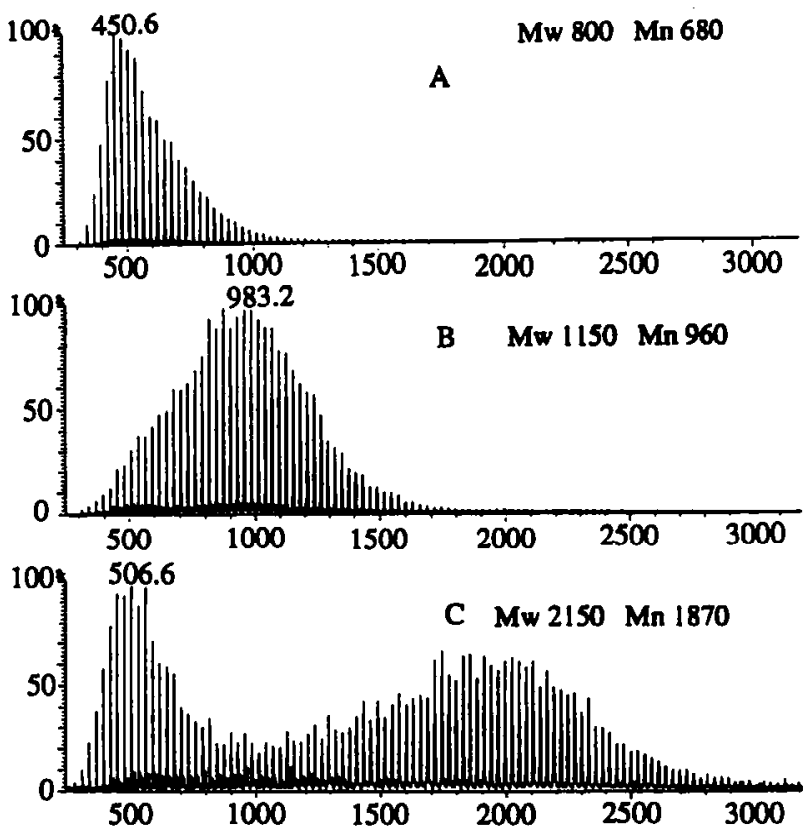

Figure 1. FD-MS data on polyethylene standards with $M_{n}=680$ (top), 960 (middle), and $1870 \mathrm{u}$ (bottom).

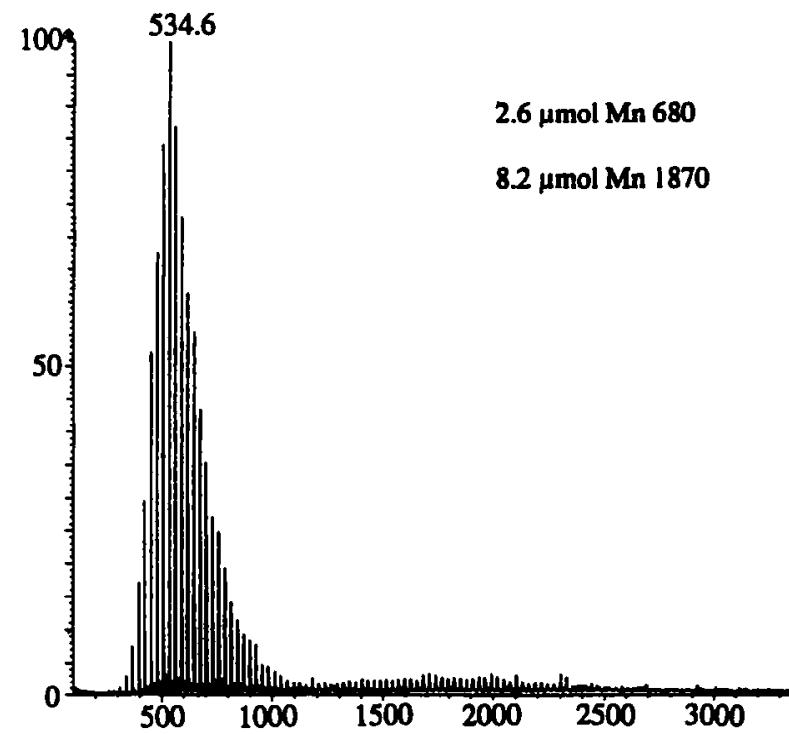

Figure 2. FD-MS data for a 1:3 mole mixture of $M_{n}=680$ - and 1870-u polyethylene standards. 
each polymer chain were separated by 28 mass units as expected for $\mathrm{CH}_{2} \mathrm{CH}_{2}$ repeat units. Each molecular ion signal was accompanied by a signal at $[\mathrm{M}-2]^{+}$ due to loss of an $\mathrm{H}_{2}$ fragment [3]. Since we did not scan below $m / z 100$, small alkyl fragment ions that may have been present were not observed.

The FD-MS spectra of standards A and B were unimodal as shown in Figure 1 (top and middle) and had $M_{n}$ values that matched those from the GPC data. However, for standard $C$, a bimodal pattern with significant intensity in the low molecular weight region was observed (Figure 1, bottom spectrum). The higher molecular weight envelope in the FD-MS data gave an $M_{n}$ value similar to that obtained by GPC. The overall bimodal distribution in the FD-MS data gave an $M_{n}$ value of $675 \mathrm{u}$, which does not match either the GPC or NMR data (Table 1). Because the low mass ions in the bimodal distribution were observed in early scans, they do not appear to be fragments or decomposition products from higher mass oligomers.

The bimodal form of the FD-MS data for standard C is unusual in consideration that the GPC data indicate a narrow molecular weight standard. In addition, there was a $>30$-fold decrease in total signal intensity as the molecular weight of the polyethylene was increased from standard $A$ to $C$. Because in a higher molecular weight sample, the number of molecules is less and more oligomers are present, reduced intensity is expected. However, based on molarity and number of oligomers, the anticipated difference in sensitivity for these samples was expected to be reduced only by a factor of approximately 7 .

To examine further the origin of the bimodal pattern of polyethylene standard $C$, mixtures of the polyethylene standards were examined by FD-MS and ${ }^{1} \mathrm{H}$ NMR spectroscopy. As shown in Figure 2, for a $1: 3$ mole ratio mixture of standards A $\left(2.1 \mathrm{mg}, M_{\mathrm{n}}=\right.$ $680 \mathrm{u})$ and $C\left(17.6 \mathrm{mg}, M_{\mathrm{n}}=1870 \mathrm{u}\right)$, the FD-MS profile was dominated by the low molecular weight polyethylene and was similar to the standard A profile with a small contribution from the higher mass oligomers. By ${ }^{1} \mathrm{H}$ NMR, $M_{\mathrm{n}}$ was found to be $1824 \mathrm{u}$ compared to a calculated $M_{\mathrm{n}}$ of $1576 \mathrm{u}$ for this mixture. Even when standards A ( $1.5 \mathrm{mg})$ and $C(55.9 \mathrm{mg})$ are mixed in a 1:14 mole ratio, the mixture still has a FD-MS profile similar to standard A (i.e., high molecular weight ions have only low abundance compared to the abundance of low molecular weight ions). For the 1:14 A:C mixture, ${ }^{1} \mathrm{H}$ NMR spectroscopy gave an $M_{\mathrm{n}}=2707 \mathrm{u}$ as compared to the calculated $M_{\mathrm{n}}=1788$ u.

These results show that there is a loss of sensitivity in the FD-MS data for the higher molecular weight ions of polyethylene. The bimodal distribution for standard $C$ appears to be due to the presence of small amounts of low molecular weight oligomers toward which FD-MS is much more sensitive. A bimodal distribution for a polyethylene sample also was reported by Lattimer and Schutten [6], but no mention was
Table 2. Analysis of polystyrene standards

\begin{tabular}{lccc}
\hline $\begin{array}{l}\text { Standard } \\
\text { polystyrene }\end{array}$ & $\begin{array}{c}\mathrm{FD}-\mathrm{MS}\left(M_{\mathrm{n}}\right) \\
(\mathrm{u})\end{array}$ & $\begin{array}{c}\mathrm{GPC}\left(M_{\mathrm{n}}\right) \\
(\mathrm{u})\end{array}$ & $\begin{array}{c}\mathrm{GPC}\left(M_{\mathrm{w}}\right) \\
(\mathrm{u})\end{array}$ \\
\hline \hline $\mathrm{D}$ & 786 & 760 & 800 \\
$\mathrm{E}$ & 1099 & 1060 & 1110 \\
$\mathrm{~F}$ & 1724 & 1690 & 1940 \\
\hline \hline Mixture & \multicolumn{4}{c}{ Calculated } \\
(molar ratio) & \multicolumn{3}{c}{$M_{\mathrm{n}}$} \\
\hline \hline $\mathrm{D}: 4 \mathrm{~F}$ & 1515 & 1518 \\
\hline
\end{tabular}

made of possible mass discrimination against higher mass oligomers. However, note that the samples used in that study were different from those used here.

The $M_{\mathrm{w}}$ and $M_{\mathrm{n}}$ data for polystyrene standards also were compared by using GPC and FD-MS and the results are summarized in Table 2. As shown in Figure 3 , accurate molecular weight distributions for polystyrene standards of $M_{\mathrm{n}}=760 \mathrm{u}$ (top spectrum), $1060 \mathrm{u}$ (middle spectrum), and $1690 \mathrm{u}$ (bottom spectrum) can be observed. There is only a fivefold drop in the signal intensities observed by FD-MS for the high molecular weight polystyrene standard compared to the low molecular weight standard. This drop is the anticipated value based on the molecular weights and the number of oligomers of each sample. A mixture of polystyrene standards $\mathrm{D}$ and $\mathrm{F}$ in a $1: 4$ mole ratio of $M_{\mathrm{n}}=760 \mathrm{u}(7.6 \mathrm{mg})$ and $M_{\mathrm{n}}=1690 \mathrm{u}(74.5 \mathrm{mg})$ gives the expected mixed distribution (calculated $M_{\mathrm{n}}=$ 1518) with the higher molecular weight ions clearly visible (Figure 4). The problem of differential sensitivity to high and low molecular weight polyethylene is not apparent with polystyrene. Therefore, FD-MS is capable of providing accurate molecular weight distri-

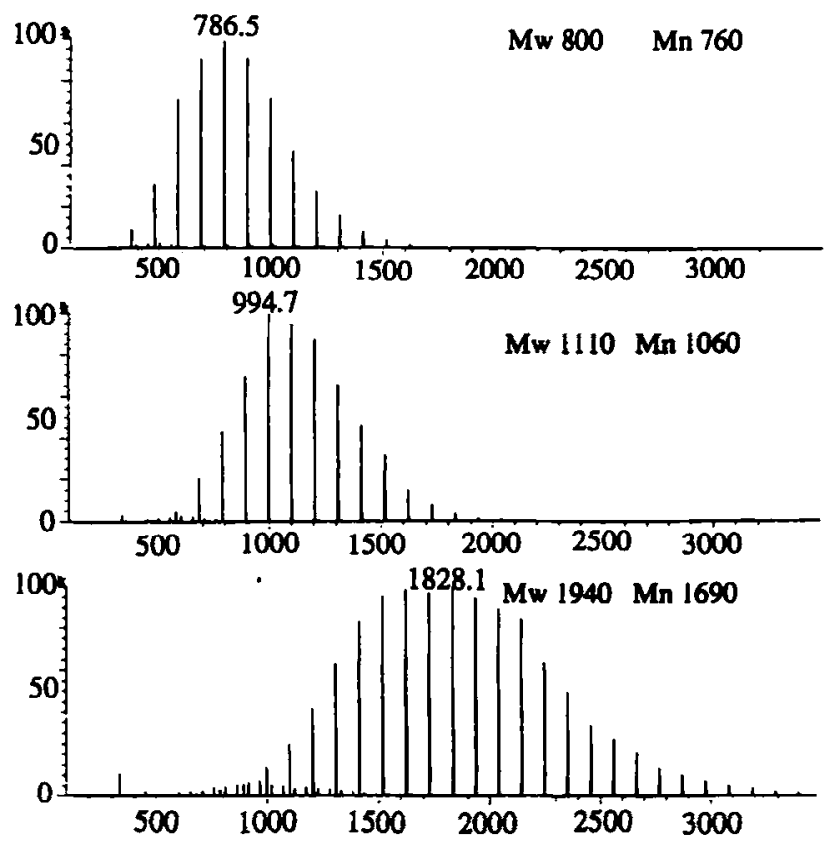

Figure 3. FD-MS data on polystyrene standards with $M_{n}=760$ (top), 1060 (middle), and $1690 \mathrm{u}$ (bottom). 


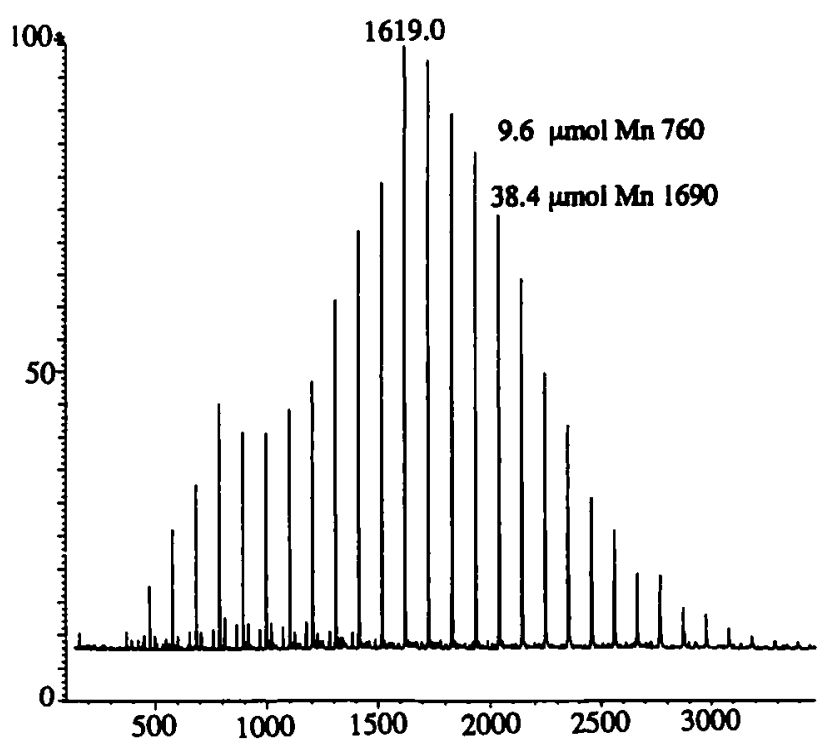

Figure 4. FD-MS data for a $1: 4$ mole mixture of $M_{\mathrm{n}}=760$ - and 1690-u polystyrene standards.

bution data on polydisperse samples for certain types of polymers. The standard data on polystyrene are in agreement with previous reports on polystyrene [7, 9], although problems with obtaining good distribution data on substituted phenyl formaldehyde tackifying resins have been reported [10].

The applicability of FD-MS in the analysis of low molecular weight straight chain hydrocarbons also was assessed. A mixture of three linear hydrocarbons, eicosane $\left(\mathrm{C}_{20} \mathrm{H}_{42}\right)$, triacontane $\left(\mathrm{C}_{30} \mathrm{H}_{62}\right)$, and tetratriacontane $\left(\mathrm{C}_{34} \mathrm{H}_{70}\right)$ in a molar ratio of $1.0: 0.51: 0.35$, respectively, was examined. As shown in the top spectrum in Figure 5, each compound gave the molecular ion as the major peak and the ratio of $\mathrm{C}_{30} \mathrm{H}_{62}$ to $\mathrm{C}_{34} \mathrm{H}_{70}$ ions is comparable to the 1.5 molar ratio in the starting material. However, the FD-MS data do not give an accurate representation of the molecular weight distribution for low molecular weight hydrocarbons. Figure 5 shows that for $\mathrm{C}_{20} \mathrm{H}_{42}$, which comprised over $50 \%$ of the mixture, a 30 -fold magnification of the molecular ion at $m / z 282$ was necessary to obtain a signal comparable in intensity to those of the less volatile components in the mixture. Furthermore, the $\mathrm{C}_{20} \mathrm{H}_{42}$ molecular ion was observed only in the first few scans taken before the emitter had been appreciably heated (emitter current $<2 \mathrm{~mA}$ ). This observation indicates that lower molecular weight oligomer chains are lost during sample introduction and are, therefore, underrepresented in spectra of low molecular weight polyethylene.

The bottom of Figure 5 shows an expanded portion of the spectrum around the molecular ion [M] ${ }^{+}$for $\mathrm{C}_{30} \mathrm{H}_{62}$ at $m / z$ 422. The ${ }^{13} \mathrm{C}$ isotope peaks for the molecular ion appear at $\mathrm{m} / \mathrm{z} 423$ and 424 and have relative intensities (35 and $6 \%$, respectively) as expected on the basis of natural abundance (calculated = $100: 34: 5.7)$. The $[\mathrm{M}-2]^{+}$ion at $m / z 420$ could arise

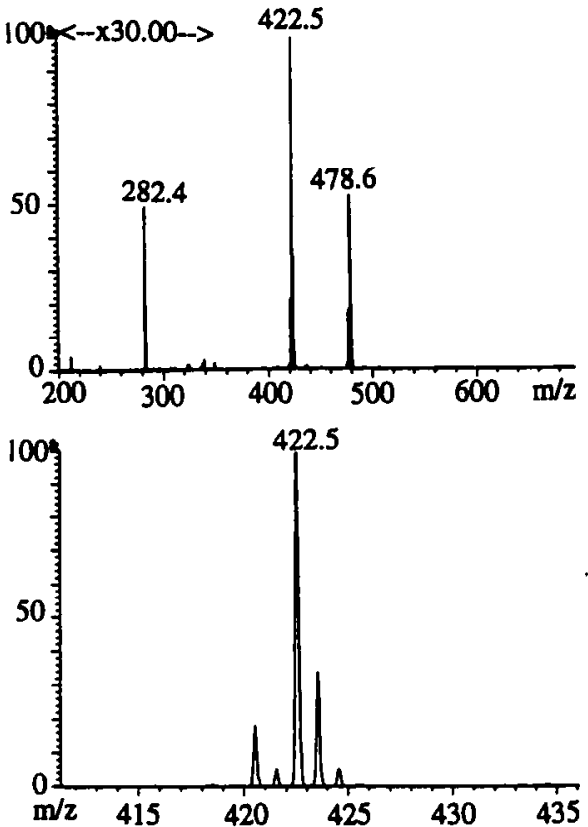

Figure 5. FD-MS data on (top) a mixture of $\mathrm{C}_{20} \mathrm{H}_{42}, \mathrm{C}_{30} \mathrm{H}_{62}$, and $\mathrm{C}_{34} \mathrm{H}_{70}$ compounds with the low molecular weight region magnified 30 times and (bottom) an expansion of the molecular ion region for $\mathrm{C}_{30} \mathrm{H}_{62}$ (mol. wt. 422).

from loss of $\mathrm{H}_{2}$ or the presence of a contaminant that is cyclic or in which there is a double bond. It was suggested previously that $[\mathrm{M}-2]^{+}$ions of this type are due to the presence of olefin impurities [6], but recent studies have shown that this ion is a fragment of the alkane and is dependent on the voltages applied [3]. Neither NMR data on triacontane nor gas chromatography-mass spectrometry data on eicosane showed any evidence of the presence of olefins in the sample, which further supports the fact that the $[\mathrm{M}-2]^{+}$ion is a fragment and not a contaminant.

\section{Conclusion}

The results show that FD-MS is of limited use in determination of the molecular weight distribution for samples of polydisperse polyethylene. Low molecular weight oligomers are underrepresented because they are volatile, whereas high molecular weight oligomers are discriminated against presumably because they are involatile. However, if the polyethylene is of narrow low molecular weight, it is possible to observe accurate molecular weight distributions. The effective mass range for which useful distributions of polyethylene can be obtained appears to be approximately 3501000 u. Although FD-MS is limited for determination of molecular weight data distribution data on polyethylene, it is a very valuable technique for analysis of polyethylene because it provides the molecular weights of the individual polymer chains that cannot be determined via other polymer analysis techniques [11]. 


\section{Acknowledgments}

We thank the National Science Foundation for support of this research and Professor Kenneth J. Shea for helpful discussions.

\section{References}

1. Beckey, H. D. Int. J. Mass Spectrom. Ion Phys. 1969, 2, 500-503.

2. Lattimer, R. P.; Schulten, H. R. Anal. Chem. 1989, 61, 1201A-1215A.

3. Heine, C. E.; Geddes, M. M. Org. Mass Spectrum 1994, 29, 277-282.

4. Kahr, M. S.; Wilkins, C. L. J. Am. Soc. Mass Spectrom. 1993, 4, 453-460.
5. Craig, A. G.; Cullis, P. G.; Derrick, P. J. Int. J. Mass Spectrom. Ion Phys. 1981, 38, 297-304.

6. Lattimer, R. P.; Schulten, H. R. Int. J. Mass Spectrom. Ion Phys. 1983, 52, 105-116.

7. Lattimer, R. P.; Harmon, D. J.; Hansen, G. E. Anal. Chem. 1980, 52, 1808-1811.

8. Rollins, K.; Scrivens, J. H.; Taylor, M. J.; Major, H. Rapid Commun. Mass Spectrom. 1990, 4, 355-359.

9. Matsuo, T.; Matsuda, H.; Katakuse, I. Anal. Chem. 1979, 512, 1329-1331.

10. Lattimer, R. P.; Hooser, E. R.; Diem, H. E.; Rhee, C. K. Rubber Chem. Technol. 1982, 55, 442 455 .

11. Evans, W. J.; DeCoster, D. M.; Greaves, J. Macromolecules 1995, 28, 7929-7936. 